\title{
Dificultades y desafíos en la educación de niños y adolescentes con discapacidad
}

\author{
Alicio Domínguez-Jara ${ }^{1}$
}

RESUMEN: No obstante la existencia de acuerdos internacionales y normativas nacionales datos actuales del Ministerio de Educación indican que son pocas las instituciones educativas que reciben en el proceso inclusivo por lo menos a un estudiante con discapacidad en Lima Metropolitana. Esta carencia evidencia la necesidad de que la educación especial cambie de enfoque para realizar un servicio educativo de calidad para todos los niños y adolescentes con discapacidad. La educación inclusiva presenta barreras que la obstaculizan. Se debe señalar que se mantiene la dificultad de acceder a la escuela debido a la distancia y a la existencia de barreras arquitectónicas. Añadidas a las barreras físicas existen otras vinculadas al modo de enseñanza. Entre los retos que enfrenta la inclusión el principal desafío es un cambio en la percepción que tenemos de las personas con discapacidad. Se debe asumir la idea de que las personas con discapacidad son titulares de derechos. Sin embargo, el mayor reto es para el Estado emprendiendo todos los esfuerzos necesarios para garantizar una educación plenamente gratuita para las personas con discapacidad.

PALABRAS CLAVE: Personas con discapacidad; Educación especial; Derechos de las personas con discapacidad; Perú.

Citar como: Domínguez A. Dificultades y desafíos en la educación de niños y adolescentes con discapacidad. CASUS. 2017;2(3):185-189. 


\section{INTRODUCCIÓN}

Ya en el 2006 la encuesta continua (ENCO) puntualizó que la población con discapacidad en edad escolar (0 a 20 años) ascendía a 373749 personas en el Perú (1). En este contexto, Lima destacaba por ser la región con mayor población de personas con discapacidad (170 349) (1). Los centros de educación básica especial (CEBE) y los programas de intervención temprana (PRITE) atendían a un población aproximada de 20899 estudiantes (2). Sin embargo, aún faltaban por recibir escolarización más de 45000 niños y jóvenes con discapacidad (2).

Se debe recordar que en 1994 la Conferencia Mundial sobre Necesidades Educativas Especiales, partiendo de la premisa de educación para todos, estableció el principio de la educación inclusiva (3). Indicando que todas las escuelas deben acoger a todos los niños sin distinción (3). Del mismo modo, la Convención sobre los Derechos de las Personas con Discapacidad (art. 24) señala que los Estados reconocen el derecho a la educación de todas las personas con discapacidad (4). Los mismos deben asegurar un sistema inclusivo en sus niveles y modalidades educativas (4).

En este sentido, en nuestro país existen también bases legales que respaldan la inclusión educativa. Entre ellas se encuentra la Ley General de Educación $\mathrm{N}^{\circ}$ 28044 (5), el Decreto Supremo N ${ }^{\circ}$ 026-2003-ED "Década de la Educación Inclusiva 2003-2012" (6). Igualmente han sido promulgadas normas para la matrícula de estudiantes con necesidades educativas especiales en Instituciones Educativas Inclusivas (7). Las cuales deben admitir o reservar al menos dos vacantes para los niños que tienen discapacidades.

No obstante esta serie de acuerdos internacionales y normativas nacionales, cifras actuales del Ministerio de Educación indican que son pocas las instituciones educativas que reciben en el proceso inclusivo por lo menos a un estudiante con discapacidad en Lima Metropolitana (8). De esta manera, en el nivel Inicial de enseñanza estuvo involucrado solo el $17.1 \%$, en primaria el $31.7 \%$ y en secundaria el $19.6 \%$ del total de las instituciones educativas (8). Los estudiantes con discapacidad incluidos en este proceso eran 56 031. De los cuales únicamente 10990 (1 de cada 6) recibían atención especializada y soporte a través de los Servicios de Apoyo y Asesoramiento de las Necesidades Educativas Especiales (SAANEE) (8).

Esta carencia evidencia la necesidad de que la educación especial cambie de enfoque para realizar un servicio educativo de calidad para los niños y adolescentes con discapacidad. Siguiendo esta perspectiva la Dirección de educación básica especial (DEBE) emitió la R.D.N ${ }^{\circ}$ 236-2010-ED que dispone que los Órganos de Gestión Psicopedagógica de los CEBE son los responsables de brindar atención a los estudiantes con discapacidad severa o multidiscapacidad (2).

Se debe recordar que en los CEBE los estudiantes pueden permanecer hasta los 20 años cumplidos. En el transcurso de los últimos años se han realizado adecuaciones respecto a las edades y niveles en la educación primaria debido en parte a las características de sus estudiantes (2). De igual manera, hasta el 2015 el equipo de SAANEE acompañaba al estudiante inclusivo. Cada docente itinerante trabajaba con un promedio de 10 a 15 estudiantes (2). En el 2016 el profesor del SAANEE estaba a cargo de 4 Instituciones educativas visitando una por día (2). El docente actualmente también tiene el objetivo de sensibilizar y capacitar a la comunidad educativa. Con el fin de acompañar adecuadamente a cada estudiante se ha indicado que se realice una visita domiciliaria para desarrollar un Plan de vida (PV), una evaluación psicopedagógica y un programa de orientación individual (POI) ajustado a sus necesidades (2).

\section{ALGUNAS DIFICULTADES DE LA EDUCACIÓN INCLUSIVA}

A modo de premisa debemos admitir que la educación inclusiva es una cuestión de derechos humanos $(3,4$, 9). Lo anterior se sustenta en que no se puede segregar a ninguna persona como consecuencia de su discapacidad o dificultades de aprendizaje, género o pertenencia a una minoría étnica $(3,4)$. Pero sobre todo es una cuestión de actitud, de un sistema de valores y de creencias. Como consecuencia, no es posible identificarla solamente con un conjunto de acciones (2).

Para hablar de las dificultades que enfrenta la educación inclusiva en el Perú es necesario indicar cuáles son las principales barreras que la obstaculizan (10). En primer lugar se debe señalar que se mantiene la dificultad de acceder a la escuela debido a la distancia y a la existencia de barreras arquitectónicas que impiden el desplazamiento de los estudiantes dentro y fuera de la escuela.

Añadidas a las barreras físicas existen otras vinculadas al modo de enseñanza $(2,10)$. Se constituye como barrera un sistema que prioriza la competitividad más que el trabajo cooperativo y solidario (2). Muchos 
profesores apenas utilizan estrategias educativas inclusivas. Generalmente, enseñan al grupo-clase como un todo sin considerar verdaderamente las diferencias. Asimismo los docentes pueden no estar del todo convencidos de que el modelo inclusivo promueve la igualdad de oportunidades. Esto se evidencia, por ejemplo, cuando hacen retornar a los CEBE a los estudiantes que "generan problemas de conducta" o "no aprenden". Igualmente, cuando el profesor del SAANEE retira del aula al estudiante inclusivo.

Por otra parte, existe una cierta presión internacional por parte de organismos y movimientos de que las normas que rigen la educación inclusiva sean uniformes. Por el otro, se manifiesta una contradicción en querer fomentar la igualdad a través de una educación para todos y simultáneamente continuar con los CEBE, formar los centros de Alto Rendimiento por regiones (COAR) o los Centros preferentes para sordos. Del mismo modo, se desea un currículo diverso para todos y a la vez se habla de adaptaciones curriculares. Una situación que en algunos docentes pudiera generar confusión.

Añadido a lo anterior tampoco se conocen adecuadamente los logros alcanzados por los estudiantes con discapacidad que participan de la educación inclusiva. Existe una tensión entre dos políticas gubernativas: por un lado se demanda una mayor inclusión y, por el otro, se exige a la escuela conseguir buenos resultados de los exámenes en la Evaluación Censal de Estudiantes (ECE). Como respuesta a este conflicto lo que suelen hacer algunas instituciones inclusivas es que los estudiantes con discapacidad no asistan el día de la evaluación para no disminuir el promedio logrado.

Finalmente, en las instituciones educativas suele haber reticencia hacia la participación de los padres de familia en el aula. Los mismos, muchas veces son percibidos como un ente fiscalizador al accionar educativo.

\section{DESAFÍOS PRESENTES Y FUTUROS}

El principal desafío es un cambio en la percepción que tenemos de las personas con discapacidad. Se debe asumir la idea de que las personas con discapacidad son titulares de derechos y no sujetos de caridad (4). Igualmente cambiar el prejuicio de que las personas con discapacidad son seres incapaces. Sino que, por el contrario, disponen de habilidades que con los medios apropiados pueden desarrollar. Esta transformación permitirá reconocer a las personas con discapacidad como parte activa del propio desarrollo y de su comunidad.

Los profesores tienen la responsabilidad de enseñar a los alumnos las competencias que necesitarán en la vida (2). Por esta razón, en gran medida dependerá de ellos el éxito del proceso inclusivo (2). Es por esto que requieren una continua capacitación, en modo tal que desarrollen buenas prácticas (2). Es decir, se formen como docentes competentes y capaces de atender a las diversas necesidades de sus estudiantes. Con esta finalidad no solo se requieren de valores y actitudes positivas, sino también de adecuadas herramientas educativas.

La preparación de estos profesionales debe contar con instancias de formación y capacitación, tanto en las etapas de la formación inicial, como en los cursos de especialización y capacitación en servicio (2). La misma debe ser destinada también a administradores escolares, planificadores educativos y encargados de formular políticas $(2,10)$. Estos profesionales deben estar habilitados para la enseñanza del lenguaje de señas y Braille. Además, deben ser conscientes de las distintas formas de discapacidad. Igualmente, estar preparados para el uso de medios y formatos de comunicación aumentativa y alternativa, así como de técnicas y materiales pedagógicos de apoyo para las personas con discapacidad (2).

Las instituciones educativas y sus autoridades tienen la responsabilidad de implementar estrategias, políticas, recursos y soportes en la comunidad educativa. Para ello se debe lograr una mayor implicación de las familias en la vida de los centros y en los procesos de planificación y desarrollo educativo (2). Para alcanzar esta meta es necesario el desarrollo de un programa de inducción antes de la matrícula para lograr un compromiso de la familia en realizar el PV y del POI.

Son numerosos los desafíos, sin embargo, el mayor reto es para el Estado peruano. El mismo debe emprender todos los esfuerzos necesarios para garantizar una educación plenamente gratuita, sin ningún costo directo o indirecto, dirigida a las personas con discapacidad. Un desafío que deberá considerar la pluriculturalidad del País.

\section{REFERENCIAS BIBLIOGRÁFICAS}

1. Instituto Nacional de Estadística e informática. Encuesta nacional continua 2006 [internet]. Lima, Perú; 2006 [citado el 01 octubre 2017]. Disponible en: https://www.inei.gob.pe/media/MenuRecursivo/public aciones_digitales/Est/Lib0692/libro.pdf 
2. Ministerio de Educación. 2012 La educación básica especial y educación inclusiva - balance y perspectivas

3. UNESCO. Declaración de Salamanca y Marco de acción para las necesidades especiales 1994 [internet]. París, Francia; 1994 [citado el 01 octubre 2017]. Disponible en: http://www.unesco.org/education/pdf/SALAMA_S.P DF

4. Convención sobre los Derechos de las Personas con Discapacidad (CDPD). Nueva York; 13 de diciembre de 2006. Nueva York: Naciones Unidas; 2006. 5. Ministerio de Educación. Ley General de Educación [internet]. Lima, Perú; 2003 [citado el 01 octubre 2017]. Disponible en: http://www.minedu.gob.pe/p/ley_general_de_educaci on_28044.pdf

6. Gobierno Peruano. Supremo $N^{\circ}$ 026-2003-ED "Década de la Educación Inclusiva 2003-2012" [internet]. Lima, Perú; 2003 [citado el 01 octubre 2017]. Disponible en: http://www4.congreso.gob.pe/comisiones/2002/discap acidad/ds/026-2003-ed.htm

7. Liliana Mayo, Santiago Cueto y Patricia Arregui. Políticas de inclusión educativa. Boletín del Consejo Nacional de Educación. N 39 diciembre 2015.

8. Ministerio de Educación. Educación especial [internet]. Lima, Perú; 2017 [citado el 01 octubre 2017]. Disponible en: http://datos.minedu.gob.pe/tags/educaci\%C3\%B3nespecial

9. Arnaiz, P. 2003. Hacia una educación eficaz para todos para todos. Ed. Aljibe. Madrid. 10. López Melero M. Barreras que impiden la escuela inclusiva y algunas estrategias para construir una escuela sin exclusiones. Innovación Educativa, 2011;21:37-54. 
ISSN 2519-0652 CASUS.2017;2(3):185-189

\section{Difficulties and challenges in the education of children and adolescents with disabilities}

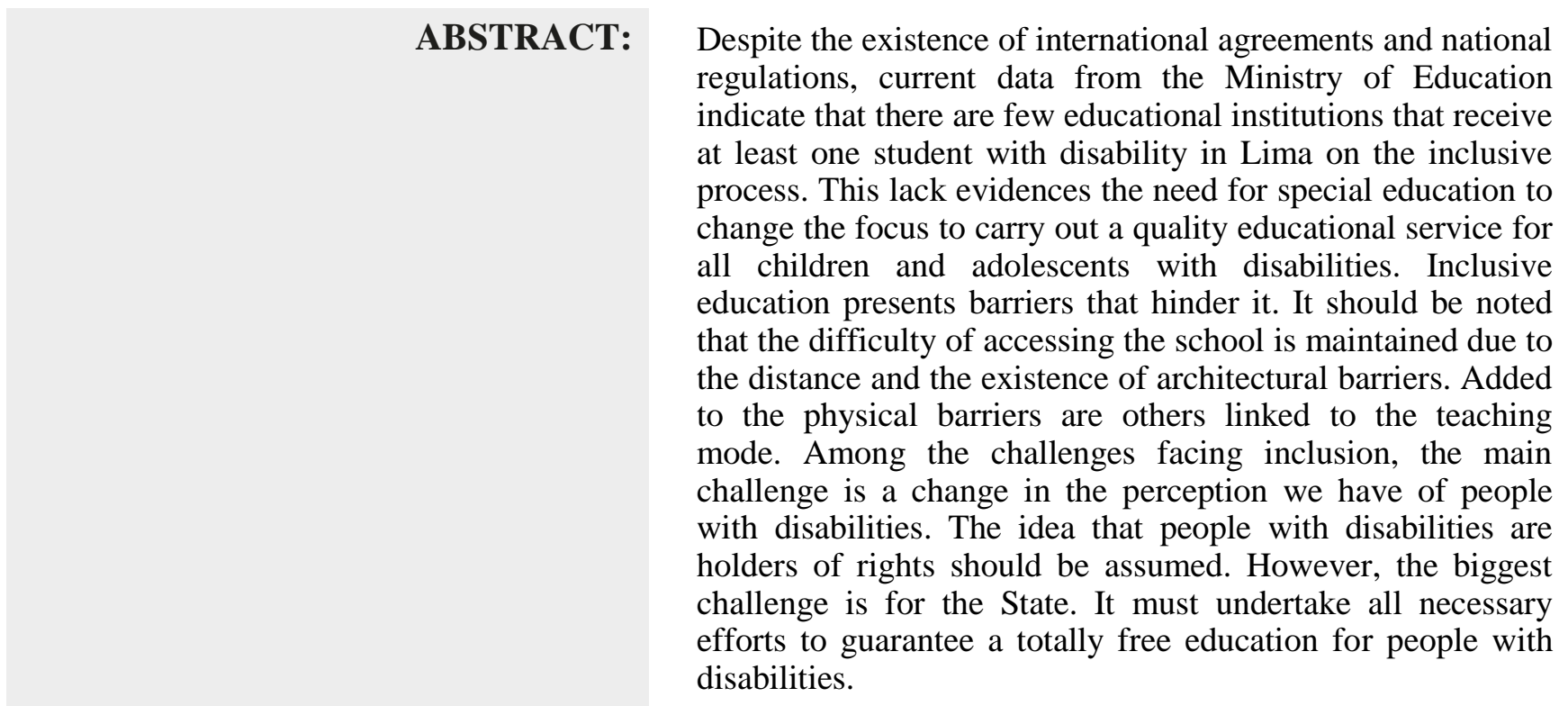

KEY WORDS: Disabled persons; Special education; Rights of persons with disability; Peru. 